Mitja Skubic

Universidad de Ljubljana

\title{
«DE CUYO NOMBRE NO QUIERO ACORDARME»
}

Palabras clave: verbo, aspecto verbal

1. Es conocida la atención que la investigación lingüística presta al sistema verbal en el romance y en el eslavo respectivamente: el primero heredó del latín una abundancia de paradigmas verbales y además enriqueció el sistema con paradigmas compuestos casi desconocidos al latín, mientras el de las lenguas eslavas es más pobre, reducido, de modo que sobre todo las relaciones temporales entre acciones y estados en las oraciones complejas no presentan la misma rigurosidad $\mathrm{u}$ ofrecen, por lo menos, interpretaciones diferentes. Sería suficiente acordarse, entre otros acontecimientos sintácticos, de la llamada consecutio temporum, de los valores temporales que expresan los paradigmas simples y compuestos, del empleo de los modos.

2. Al contrario de la abundancia de los paradigmas temporales en las lenguas románicas, en el sistema de las lenguas eslavas el verbo conoce otra característica, en el romance sólo parcialmente sensible y, si es que existe, entrelazada con la del empleo de varios paradigmas temporales, llamada aspecto verbal, en esloveno y en los idiomas eslavos glagolski vid. Se sabe que el término se debe, probablemente, a una errónea interpretación del griego $\varepsilon 1 \delta$ o $\varsigma$ que en origen significa 'especie, categoría', y sólo en seguida 'manera de ver' que es, así parece, el punto semántico de base para el término glagolski vid 'aspecto verbal' de las lenguas eslavas. El término adquirió el significado de cómo el hablante ve la limitación del acontecimiento expresado por el verbo. Con la oposición perfectivo: imperfectivo los paradigmas verbales manifiestan el contenido interior del verbo y no sólo la extensión temporal o precisión modal. Como nos limitaremos en seguida a comparar la situación en español y en esloveno, conviene quizás añadir que en éste casi todos los verbos, a excepción hecha por los verbos modernos recién aceptados en la lengua como telefonirati 'telefonear', organizirati 'organizar, arreglar' y algunos otros pocos, p. ej. ubogati 'obedecer', podariti 'regalar', conocen esta duplicidad aspectual y, sea subrayado, en todos los paradigmas temporales (véase Toporišič, 1976: 285). Es decir, la oposición en romance sin duda de carácter aspectual de los verbos en una oración como Juan estaba en casa, cuando entró Francisco, en esloveno no está expresada, como en español, además de las dos raíces distintas también con los dos paradigmas verbales de la esfera del pasado, sino sólo mediante el significado de los dos verbos empleados.

3. El concepto aspectual es herencia del indoeuropeo; con el aoristo lo conoce el griego, hay algunos restos esporádicos también en latín, como p. ej. CUBARE: (SUC) CUMBERE. Cítase la convicción de Saussure (1980, pár. 162): según el ilustre lingüista 
ginebrino el francés no posee las posibilidades de expresar la oposición aspectual ${ }^{1}$. Ya Bello (Bello, 1928, 625a) hacía distinción entre verbos desinentes y permanentes. Gili Gaya (1961: 119) exploró magistralmente el problema. Un panorama detallado lo encontramos en la Nueva gramática del español de la Real Academia Española (2009: 1685 ss). Es conocido que el latín y con él las lenguas romances han dado una preferencia absoluta a la expresión del tiempo y por eso se ha oscurecido la noción del aspecto que tuvo que existir en el indoeuropeo. No por completo: no es sólo semánticamente, por medio de dos raíces distintas, sino también por las perífrasis verbales y por los paradigmas verbales del pasado que el hablante español puede expresar el acontecimiento verbal en su visión como perfectivo o imperfectivo. El aspecto verbal es las más veces considerado categoría de la limitación del acontecimiento verbal y con esta visión en español también surge el problema de separar la noción de aspecto verbal de aquella de modo de acción. $\mathrm{Si}$ en la primera tenemos que ver un fenómeno sintáctico, en la segunda es predominante el carácter lexical, es decir, el contenido semántico. La Nueva gramática de la RAE, cp. 23.2c, ofrece una tripartición con a) aspecto léxico o modo de acción, es decir, una especie de supletivismo aspectual, b) aspecto sintáctico o perifrástico, c) aspecto morfológico o desinencial. Esta tripartición es valedera sin duda para el español, pero no encuentra una imagen del todo adecuada en esloveno y en el sistema eslavo en general. Así, en el pár. 23.2a de la gramática de la RAE se comparan las oraciones Arturo lee el periódico y Arturo está leyendo el periódico donde en la primera, se explica, «se puede hablar de cierto suceso repetido», mientras «la interpretación de suceso repetido se descarta en la segunda oración». Si la constatación que relaciona el valor de la perífrasis con el verbo estar es impecable y eminentemente española, no por esto podemos ver una repetición del acto verbal en la primera; por lo menos, no la repetición de un verbo perfectivo, y analizando el valor de la forma del verbo desde la concepción del aspecto verbal vigente en las lenguas eslavas, ya que la podemos constatar eventualmente sólo en un contexto apropiado, p. ej. lee el periódico antes de acostarse. Un ejemplo banal podría, quizás, ilustrar el procedimiento sintáctico: en una tienda de zapatos una española está eligiendo zapatos y después de la seleción los elige, mientras una italiana a una pregunta sobre qué está haciendo puede contestar simplemente scelgo scarpe y decir, después de haber efectuado la elección, scelgo queste. El empleo de la estructura con el verbo semi-auxiliar sto scegliendo es en italiano (y en francés con je suis en train de) sólo una posibilidad opcional, no obligatoria. Al contrario, constatamos que el esloveno en tal situación lingüística concuerda por completo con el español, sirviéndose de la oposición entre las dos realizaciones aspectuales del mismo verbo: izbirati (imperfectivo) e izbrati (perfectivo).

Dentro del marco de las lenguas románicas la noción del aspecto verbal ha sido aceptada desigualmente por los lingüístas: hay quienes niegan tal existencia o, por lo menos, rechazan la posibilidad de parangonar las aisladas apariciones en el romance con el sistema en lenguas eslavas y creen, así L. Jenaro Maclennan (1962: 31), que la concep-

Las lenguas eslavas distinguen regularmente dos aspectos del verbo: el perfectivo representa la acción en su totalidad, como un punto, al margen de todo devenir; el imperfectivo la muestra haciéndose, y en la línea del tiempo. Estas categorías presentan dificultad para un francés porque su lengua las ignora. - Cita según la traducción castellana, CLG, Madrid (1980: 165). 
ción y los términos son propiedad del eslavo «de cuyo seno jamás debieron salir». Pero, la mayoría acepta lo que ofrece la lingüística en el campo eslavo y procura delimitar las apariciones aspectuales en las del léxico y las del sistema sintáctico con perífrasis verbales. Es obvia también la tercera clase de indudable valor, la más evidente por lo menos desde los análisis sobre el verbo romance de Antoine Meillet percibida en la oposición perfectum: infectum. En la tripartición de la RAE está clasificada como el aspecto morfológico o desinencial (cantó - cantaba).

4. El intento aquí es el de averiguar si un hecho sintáctico, el empleo de la forma reflexiva del verbo, puede ofrecer un medio para establecer la oposición perfectividadimperfectividad. La idea está iluminada ya en Gili Gaya (1961, pár. 118), donde se constata que «el verbo enojarse 'comenzar a sentir enojo' toma aspecto incoativo, que no tiene el verbo enojar, por la añadidura del pronombre». Lo mismo, siempre según Gili Gaya, ocurre con el verbo dormir - dormirse, cfr. de Rinconete y Cortadillo Durmiéronse, vino el día en Novelas ejemplares. Los demás idiomas romances, aquí, no concuerdan por completo con la situación en español y exigen en este verbo un prefijo: cfr. el italiano addormentarsi o el francés s'endormir, procedimento tampoco desconocido en el español, adormecerse. Cabe añadir que el significado de un verbo casi-reflexivo puede ya no ser lo mismo que el del verbo simple. Leemos en El Qujote: Sería acertado irnos a retraer a alguna iglesia (I, 10); El daño estuvo - dijo don Quijote-en irme yo de alli, que no me había de ir hasta dejarte pagado (I, 31); Y con esto se fue el ama, y el bachiller fue luego a buscar al cura (II, 7). La forma reflexiva impone al verbo el matiz de perfectividad.

5. Nuestro interés fue suscitado por las palabras con las cuales Cervantes empieza la narración de los acontecimientos de su caballero andante. Se aducirán algunos ejemplos del Quijote y de las Novelas ejemplares y otros, muy pocos, de la Biblia, éstos con el solo fin de poder hacer la comparación con el español contemporáneo. En los pasajes se quiere averiguar, si las traducciones al esloveno pueden confirmar la idea de estar expresado el aspecto, en este caso la perfectividad, mediante la forma reflexiva del verbo. Nos limitamos, cierto, al español y a las obras literarias mencionadas, transgrediendo esto una sola vez, donde nos ha movido el emocionante empleo del mismo verbo en la análoga forma casi refleja y, más que otro, el deseo de inclinarse a otro genio creador: Dante Alighieri en su poético viaje a través de los tres reinos de allende hace suspirar a Francisca de Rimini: Nessun maggior dolore che ricordarsi del tempo felice ne la miseria. (Inferno, V, 121-123).

6. Antes de hacer dicha comparación con los pasajes traducidos al esloveno cabe presentar en pocas líneas las manifestaciones del aspecto en el verbo esloveno. Tratamos exclusivamente el fenómeno sintáctico, es decir, queremos hacer ver que el esloveno, como las demás lenguas eslavas, conoce el modo de expresar el acontecimiento verbal mediante dos distintas raíces, es decir, conoce el empleo del supletivismo como el español, y, además, por medio de las perífrasis verbales con los verbos semi-auxiliares; tal procedimiento permite expresar el comienzo o el fin de una acción. Pero, en general, de un verbo imperfectivo, y tal es en esloveno la mayoría, se forma un verbo perfectivo me- 
diante un prefijo, mientras de un verbo perfectivo, también secundario, se puede formar un imperfectivo mediante un sufijo. Para el verbo en la oración cervantina que suscitó nuestro interés, es decir acordar(se), he aquí el reflejo esloveno: pomniti 'recordar' spomniti (se) 'acordar(se)' y además el imperfectivo (secundario, con la modificación en el tema del verbo) spominjati (se). Creemos que la oposición aspectual en esloveno entre spominja na očeta in spomni se očeta sea idéntica a la española recuerda a su padre y se acuerda de su padre.

Comparando el original español y las dos traducciones íntegras eslovenas de la novela cervantina (Leben, 1935-37, Košir, 1958) y aquella de las Novelas ejemplares (Debeljak, 1951) se constata que el verbo reflexivo en español a menudo viene traducido con el verbo perfectivo. Sería suficiente citar la versión eslovena además del título de estas nuestras líneas ...čigar imena se ne želim spomniti otro pasaje con el mismo verbo: Si vuestra merced tuviera buena memoria - replicó Sancho-, debiérase acordar (II, 20) 'če bi vaša milost imela dober spomin, bi se morala spomniti'. Por lo visto, los dos traductores, ambos de un afilado sentido lingüístico, sintieron en cierto modo en el reflexivo acordarse un rasgo de momentaneidad de la acción y con esto la perfectividad. Podemos citar en seguida pero sólo en el original: Plégaos, señora, de membraros deste vuestro sujeto corazón (I, 2); Que los diablos lleven la cosa que de la carta se me acuerda (I, 26); Porque de todos los puntos esenciales que en este suceso me acontecieron ninguno se me ha ido de la memoria, ni aun se me irá en tanto que tuviere vida (I, 40); No me acuerdo haber leído que ningún caballero andante haya señalado conocido salario a su escudero (II, 7); A no olvidársele todo aquello de que quería acordarse (II, 45); Yo en este caso no he hablado de mío, sino que se me vino a la memoria un precepto (II, 51); Ha querido Dios que agora se me acordase (II, 51). Encontramos pasajes análogos en las Novelas ejemplares: Acuérdate (I, 44); No es por falta de memoria habérsete olvidado el nombre de tu patria (I, 243); Nadie se olvide de lo que dice el Espíritu Santo (I, 169); Acuérdaseme que cuando yo era hombre de carne, y no de vidrio como agora soy (II, 56); Se me acordare (II, 213; Decir lo que ahora se te acuerda (II, 213); Sin acordarse señor el viejo (II, 230); Acuérdome que cuando estudiaba, oí decir (II, 256). En los pasajes citados la versión eslovena muestra el verbo en el aspecto perfectivo.

Añadimos algunos pasos de la Sagrada Biblia, repetimos, sólo para ver si hay uso análogo en las traducciones, española y eslovena, hechas en nuestros días:

Hijo mío, no te olvides de mis enseñanzas (Proverbios, 3, 1); Yo, al acordarme, me horrorizo, (Job, 21, 6): Acuérdate de esto: el enemigo blasfema de Jahve (Psalmos, 74, 18); Me acuerdo de Dios y gimo (Salmos, 77, 4); Se acordó de que eran de carne (Salmos, 78, 39); Acuérdate de cuán breve es la vida (Salmos, 89, 48); Acuérdate de la palabra dada (Salmos, 119, 49). Las citas correspondientes de la versión eslovena ofrecen, todas, el verbo en forma perfectiva. Hay todavía también otras, donde aparece el verbo en su realización imperfectiva, sobre todo en las oraciones negativas, en particular en las prohibiciones y por entonces congruentes con el espíritu del texto bíblico. En complejo, pero, para el verbo escogido predominan pasajes donde con la forma casi refleja constatamos expresada la perfectividad. 
7. Podemos concluir que la noción de aspecto stricto sensu está efectivamente reservada al verbo eslavo, aunque las manifestaciones del aspecto no son desconocidas al verbo romance. Tomando como prueba sólo el verbo que titula nuestra contribución, y pocas otras veces un verbo del mismo o cercano, a veces también del opuesto campo semántico, como membrar(se), venir(se) a la memoria, irse de la memoria, olvidar(se), hemos creído útil la comparación de algunos pasajes literarios en español, empezando con los de El Quijote, con las traducciones en esloveno: en muchos de ellos el verbo esloveno con aspecto perfectivo aparece en pasajes donde el original español lleva la forma reflexiva. Tal vez, este empleo es una modesta posibilidad de establecer por lo menos en algunos verbos la oposición aspectual.

\section{BIBLIOGRAFÍA}

Bello, A., Cuervo, R. J. (192823): Gramática de la lengua castellana. París: Andres Blot.

Cervantes, Miguel de (2004): Don Quijote de la Mancha. Madrid: Edición del Instituto Cervantes.

Cervantes, Miguel de (1935-37): Bistroumni plemič Don Kihot iz Manče. Ljubljana: Slovenska Matica.

Cervantes, Miguel de (1973): Veleumni plemič Don Kihot iz Manče. Ljubljana: Mladinska knjiga. Cervantes, Miguel de (1905?): Novelas ejemplares. Valladolid: Jorge Montero.

Cervantes, Miguel de (1951): Zgledne novele. Ljubljana: Slovenski knjižni zavod v Ljubljani.

Gili Gaya, S. $\left(1970^{9}\right)$ : Curso superior de sintaxis española. Barcelona: Bibliograf.

Jenaro Maclennan, L. (1962): El problema del aspecto verbal. Madrid: Gredos.

Real Academia Española/Asociación de Academias de la Lengua Española (2009): Nueva Gramática de la Lengua Española. Madrid: Espasa.

Sagrada Biblia. (1970). Madrid: Biblioteca de los autores cristianos.

Saussure, F. de (1980): Curso de lingüistica general. Madrid: Akal editor.

Toporišič, J. (1976): Slovenska slovnica. Maribor: Založba Obzorja. 


\section{»ČIGAR IMENA SE NE ŽELIM SPOMNITI«}

Ključne besede: glagol, glagolski vid

Glagolski vid je docela zadeva slovanskih jezikov. Je pa bilo zmeraj vprašanje za romansko jezikoslovje, ali je mogoče tudi v romanskem glagolu zaznati razlikovanje med dovršnostjo in nedovršnostjo, kar je nedvomno ugotovljivo, tako kot v slovanskih jezikih, v izbiri in pomenski opoziciji glagolov kot reči - govoriti, kjer se jasno izrazi glagolska vrstnost. Podobno velja za rabo tistih glagolskih perifraz, kjer se izražanje omeji na začetek ali konec glagolskega dejanja in ne na aspekt. V prispevku se skuša ugotoviti, ali je povratna oblika glagola, vsaj nekaterih glagolov, za primer je vzet španski glagol acordarse - spomniti se, za nekatere glagole možnost, da se tudi v španščini izrazi dovršno dejanje, torej vsaj pri nekaterih glagolih glagolski vid, aspekt. 